\title{
Cost-effectiveness of a school-based Tay-Sachs and cystic fibrosis genetic carrier screening program
}

Emma Warren, $\mathrm{MA}^{1}$, Rob Anderson, PhD, MSc ${ }^{1}$, Anné L. Proos, MSc ${ }^{2,3}$, Leslie B. Burnett, PhD, FRCPA ${ }^{2,3}$, Kris Barlow-Stewart, PhD, FHGSA ${ }^{4}$, and Jane Hall, $P h D^{1}$

\begin{abstract}
Purpose: To explore the cost-effectiveness of school-based multidisease genetic carrier screening. Method: Decision analysis of the cost-effectiveness of a school-based Tay-Sachs disease and cystic fibrosis genetic carrier screening program, relative to no screening. Data relating to ethnicity profile, test-accepting behavior, and screening program cost were sourced from an existing program in Sydney, Australia. Results: Compared to no screening, the incremental cost-effectiveness of the screening program is $A \$ 5,834$ per additional carrier detected. This cost-effectiveness ratio is most sensitive to changes in genetic test accuracy, and the cost of laboratory assays. The results imply a cost per affected birth avoided of approximately $A \$ 530,000(\approx$ US $\$ 371,000)$. Conclusions: This preconceptional genetic carrier screening program offers comparable cost-effectiveness to prenatal screening programs for cystic fibrosis. Genet Med 2005:7(7):484-494.
\end{abstract}

Key Words: genetic carrier screening, cost-effectiveness, Tay-Sachs, cystic fibrosis, school

Tay-Sachs disease (TSD) is a neurodegenerative genetic disorder that results in progressive neural dysfunction from infancy, leading to death, usually by 5 years of age. ${ }^{1}$ TSD is most prevalent in the Ashkenazi Jewish population (Jewish individuals of Eastern European ancestry) with a genetic carrier rate of 1 in 28 compared to 1 in 250 to 280 in the general population. ${ }^{2,3}$ There is currently no effective treatment for TSD. Cystic fibrosis (CF) is the most prevalent autosomal recessive genetic disorder among newborn Caucasians, and in the classic form leads to chronic lung infection and pancreatic insufficiency. It varies in severity but, even with presently available treatments, is often fatal by the age of 40 . The genetic carrier rate in the general Australian population has been estimated as approximately 1 in $26.4,5$

The rationale for preconceptional genetic carrier screening is that awareness of carrier status can influence reproductive choices; couples where both partners are known genetic carriers may alter their plans to have a family, or use reproductive techniques that allow them to avoid having an affected child. Further, in some Orthodox religious Ashkenazi Jewish communities it is an accepted practice to avoid marriages between

From the ${ }^{1}$ Centre for Health Economics Research and Evaluation (CHERE), University of Technology Sydney, Sydney, NSW, Australia; ${ }^{2}$ Pacific Laboratory Medicine Services (PaLMS), Royal North Shore Hospital, St Leonards, NSW, Australia; ${ }^{3}$ Kolling Institute of Medical Research, Northern Clinical School, University of Sydney, Royal North Shore Hospital, St Leonards, NSW, Australia; ${ }^{4}$ The Centre for Genetics Education of the NSW Genetics Service, Royal North Shore Hospital, St Leonards, NSW, Australia.

Dr R Anderson, PenTAG, Noy Scott House, Royal Devon \& Exeter Hospital (Wonford), Barrack Road, Exeter EX2 SDW, United Kingdom.

Received: March 14, 2005.

Accepted: May 25, 2005.

DOI: 10.1097/01.gim.0000178496.91670.3b known genetic carriers of a number of genetic disorders common in these communities, including TSD and CF. ${ }^{6}$

To date there have been few economic evaluations of genetic carrier screening, and most assess the value of prenatal screening (i.e., testing during pregnancy) as opposed to preconceptional population screening. Several economic evaluations of prenatal CF genetic carrier testing exist (i.e., testing of expecting couples), ${ }^{7-10}$ and there is an early study of the resource implications of TSD carrier screening. ${ }^{11}$ To our knowledge, a 1998 study in the Netherlands is the only one to assess the cost-effectiveness of both prenatal and school-based CF carrier screening. ${ }^{12}$ More recent evaluations of school-based preconceptional screening, ${ }^{13}$ and a closer investigation of the longstanding Montreal screening program, ${ }^{3,14}$ would allow more realistic assumptions about the effectiveness of school-based genetic carrier screening than those used in the Wildhagen study. School-based screening also involves offering testing when people are mature enough to make mature decisions about testing, ${ }^{15}$ and-being preconceptional-the information generated can inform the widest range of reproductive choices.

A school-based genetic carrier screening program for TSD has been operational in Sydney in Jewish community High Schools for 9 years. Sydney is the largest city in Australia (population 4 million), ${ }^{16}$ and has a Jewish population of around 50,000 , of whom over $90 \%$ are Ashkenazim. The carrier screening program combines a compulsory genetics education program with a voluntary genetic carrier testing scheme. Genetic carrier screening is offered to all students in the participating schools during their penultimate year of school (16- or 17-year-old senior High School students) and is free of charge. From 1997-2000, the program also operated on a research basis in an additional six secular Government High Schools 
within the metropolitan Sydney area. These six schools were multiethnic and selected on the basis of expected high numbers of Ashkenazi Jewish students. During this period, CF genetic carrier testing was also offered.

This study examines preconceptional genetic carrier screening for TSD and/or CF in an Australian policy setting and is based on data obtained from the Sydney program as it was offered in 2000 in 9 of the 10 participating schools (hereafter called the "reference program"). The main features of the reference program are described in the Appendix (Box 1); a fuller description of the program in Jewish schools has been published elsewhere. ${ }^{13}$

The main aim of this study was to assess the cost-effectiveness of the Sydney school-based reference carrier screening program, compared with the hypothetical absence of the program. A decision-modeling approach was used to integrate the cost and effectiveness data from various sources and to allow exploration of the impact of key or uncertain variables and assumptions. ${ }^{17,18}$ The economic evaluation has been performed from a health sector perspective; because the implicit policy choice-of whether to provide such screening programs-is usually that of a service funder.

Whereas the value of population-based genetic carrier screening for disorders such as $\mathrm{CF}$ is associated with a number of complex issues and problems, and is most often offered in the prenatal setting, it has been acknowledged that preconceptional testing is preferred by the community and should be encouraged wherever possible. ${ }^{19-21}$ Knowledge of the cost-effectiveness of preconceptional screening programs should inform the debate about their wider possible implementation. Further, in multiethnic communities like those in Australian and US cities, offering genetic carrier testing for a number of genetic disorders at the same time is an obvious way to gain greater benefits from the largely fixed resources tied up in such screening programs. Multidisorder genetic carrier screening programs are not common (at least in the published literature), but might become the norm as more and possibly cheaper mutation tests become available, and as populationspecific knowledge of genotypic variation expands. ${ }^{22}$ This study should therefore also be regarded as a first step in exploring some of the methodological issues that this raises.

\section{METHODS}

\section{Overview of the model}

A model was developed to estimate the cost-effectiveness of the school-based carrier screening program compared to a hypothetical situation in which there is no school-based screening program (i.e., its incremental cost-effectiveness). Such mathematical models simulate a hypothetical cohort of patients/people, using a number of assumptions about the costs that they will incur, and the outcomes they will experience, by following various pathways. ${ }^{23}$ Ultimately it then synthesizes (or "adds up") the accumulated cost and outcome data for all modeled subjects and provides a total cost and effectiveness estimate for each policy or screening strategy being simulated.

Our model has been structured to reflect: the ethnic composition of participating schools; the main pathways by which students access genetic carrier screening; the possible combinations of tests accepted, and possible combinations of test results. Figure 1 shows a simplified representation of the model. The model was constructed in dedicated software for such decision analytic modeling (DATA 4.0 from TreeAge Software Inc., Williamstown, $\mathrm{MA}$ ) and is described fully in a separate report (downloadable as a PDF file from www.chere.uts.edu.au). ${ }^{24}$

\section{The main policy alternative: No screening program}

The comparator, "no program," submodel shown in Figure 1 represents the most likely test-accessing and follow-up pathways that the same students would follow if their schools were

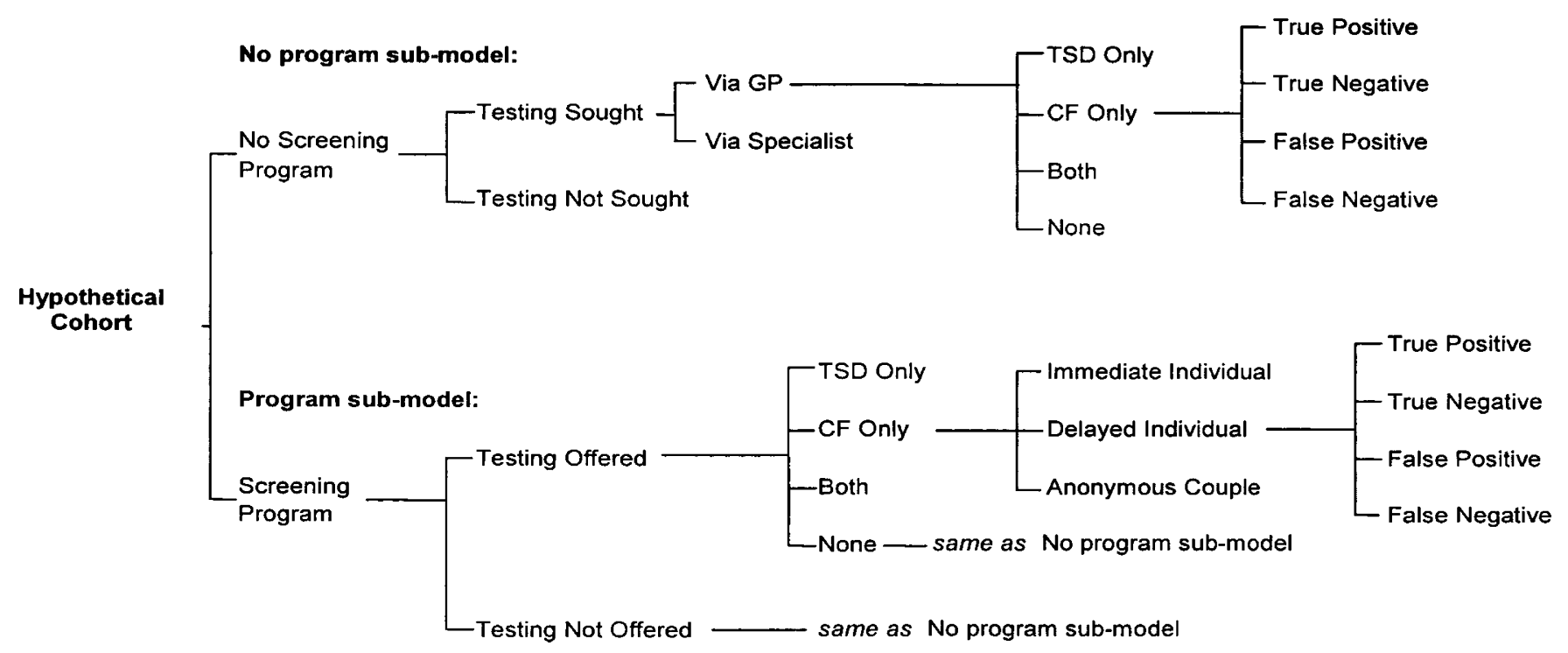

Fig. 1. Simplified representation of the decision model 
Table 1

Probability estimates in the decision model (and range used in sensitivity analysis)

\begin{tabular}{|c|c|c|c|c|}
\hline \multirow[b]{2}{*}{ Variable description } & \multicolumn{3}{|c|}{ Ancestry } & \multirow[b]{2}{*}{ Source } \\
\hline & Ashkenazi Jewish & $\mathrm{CNJ}$ & Other & \\
\hline \multicolumn{5}{|l|}{ Ethnic profile of school populations: } \\
\hline Overall \% of students in participating schools & $40 \%$ & $25 \%$ & $35 \%$ & $a$ \\
\hline \multicolumn{5}{|l|}{ True genotype } \\
\hline Genetic carrier prevalence for TSD & 0.036 & 0.004 & 0.004 & $b$ \\
\hline Genetic carrier prevalence for CF & 0.033 & 0.040 & 0.007 & $c$ \\
\hline \multicolumn{5}{|l|}{ Sensitivity and specificity of tests } \\
\hline TSD test sensitivity & 0.98 & 0.98 & 0.98 & $d$ \\
\hline TSD test specificity & 0.98 & 0.94 & 0.94 & $d$ \\
\hline CF test sensitivity & 0.95 & 0.75 & 0.05 & $d$ \\
\hline CF test specificity & 0.999 & 0.999 & 0.999 & $d$ \\
\hline \multicolumn{5}{|l|}{ Test-accepting behavior } \\
\hline $\begin{array}{l}\text { Proportion of students offered testing at } \\
\text { school who have testing for TSD }\end{array}$ & $0.8(0.6-0.9)$ & $0.4(0-0.5)$ & $0.2(0-0.3)$ & $e$ \\
\hline $\begin{array}{l}\text { Proportion of students offered testing at } \\
\text { school who have testing for CF }\end{array}$ & $0.8(0.7-0.9)$ & $0.8(0.7-0.9)$ & $0.3(0-0.4)$ & $e$ \\
\hline $\begin{array}{l}\text { Proportion of students who access testing for } \\
\text { TSD (in no screening program sub-model) }\end{array}$ & $0.05(0-0.2)$ & $0(0-0.01)$ & $0(0-0.01)$ & $f$ \\
\hline $\begin{array}{l}\text { Proportion of students who access testing for } \\
\text { CF (in no screening program sub-model) } \\
\text { ( }{ }^{*} \text { For Jewish students this is the proportion } \\
\text { of those who access TSD testing who also } \\
\text { access CF testing) }\end{array}$ & $0.8^{*}(0.7-0.9)$ & $0.01(0-0.05)$ & $0.01(0-0.05)$ & $f$ \\
\hline \multicolumn{5}{|l|}{ Result notification scheme } \\
\hline $\begin{array}{l}\text { Proportion of students in year } 11 \text { who attend } \\
\text { the education and collection day (and thus } \\
\text { are offered testing) }\end{array}$ & $0.91(0.8-1)$ & $0.91(0.8-1)$ & $0.91(0.8-1)$ & $e$ \\
\hline $\begin{array}{l}\text { Proportion of students who elected to receive } \\
\text { a delayed result }\end{array}$ & $0.1(0-0.2)$ & $0(0.05-0.1)$ & $0(0.05-0.1)$ & $g$ \\
\hline $\begin{array}{l}\text { Proportion of students with a delayed result } \\
\text { who actually access the information in the } \\
\text { future }\end{array}$ & $0.4(0-1)$ & $\cdots$ & $\cdots$ & $h$ \\
\hline $\begin{array}{l}\text { Proportion of students with a delayed result } \\
\text { who receive their result as an individual }\end{array}$ & $0.8(0.5-1)$ & $\ldots$ & $\ldots$ & $i$ \\
\hline $\begin{array}{l}\text { Proportion of individuals with a positive test } \\
\text { result who access additional counseling }\end{array}$ & $0.05(0-0.1)$ & $0.05(0-0.1)$ & $0.05(0-0.1)$ & $i$ \\
\hline
\end{tabular}

${ }^{a}$ From questionnaire surveys of students participating in education sessions in 2000 (nine schools).

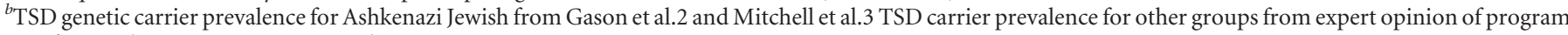
coordinator (a senior genetic scientist)

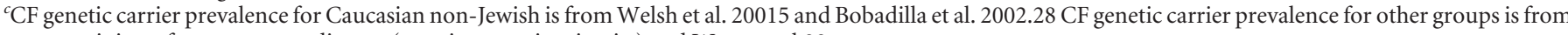
expert opinion of program coordinator (a senior genetic scientist) and Wong et al.29

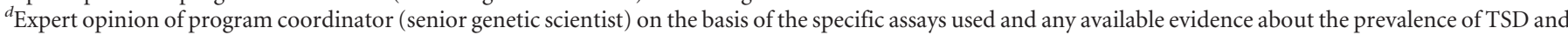

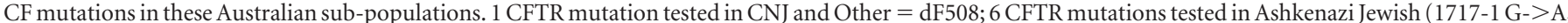
G542X, W1282X, N1303K, dF508, 3849+10kbC->T.). TSD testing amongst Ashkenazi Jewish is by enzyme testing (and HEXA 3 mutation testing if needed)

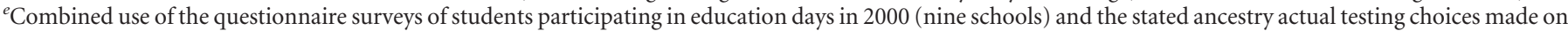
specimen collection day documentation.

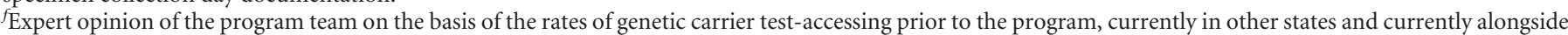
the program.

${ }^{g}$ Screening program documentation (e.g., consent forms)

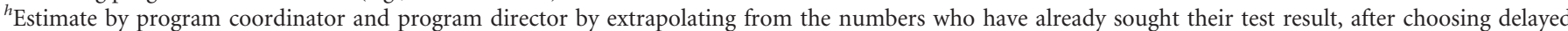
notification (which has been offered since 1997).

${ }^{i}$ Expert opinion of the program team. 
not involved in the school-based screening program. Unfortunately, even though preconceptional genetic testing for TSD and CF genetic carriers occurs without a definitive screening program in some Australian States, there is very little evidence regarding the current scale or cost of these activities. Trials of CF genetic carrier screening in general practice settings in the UK may not be indicative of realistic alternatives in the Australian general practice context. ${ }^{25-27}$ The Appendix (Box 2) therefore lists the main assumptions that together constitute the "no program" submodel (Tables 1 and 2 for their quantitative expression). These assumptions were developed through discussion with the program managers, and some correspondence with medical geneticists in other Australian states.

Even greater uncertainty surrounds how widely genetic carrier testing will be available, promoted, or taken up in the fu- ture. Thus the assumptions underlying the comparator submodel were varied widely in the sensitivity analysis.

\section{Population characteristics reflected in the model}

The model classifies students into the main ethnic groups in the Australian population that determine their genotype for TSD and CF, their test-accepting behavior, and also the sensitivity and specificity of each genetic test. The students were asked two questions regarding their ethnicity. The first inquired if they were Jewish. In recognition of the fact that Australia is a multicultural society made up of people from many parts of the world, the second asked them to indicate if their family came from the following parts of the world: Northern European (including England, Scotland, Wales, and Ireland); Asian (including China, Hong Kong, Japan, and South East

Table 2

Cost estimates in the decision model and ranges for sensitivity analysis

\begin{tabular}{|c|c|c|c|}
\hline \multirow{2}{*}{$\frac{\text { Cost ingredient }}{\text { "One-off" costs of establishing the program }}$} & Value A\$ (range) & & \multirow{2}{*}{$\frac{\text { Sources and notes }}{a}$} \\
\hline & $(11,109-37,115)$ & & \\
\hline Annual recurring cost of running the program & $(7,104-10,221)$ & & $a$ \\
\hline Annual cost of retaining a school in the program & $(365-896)$ & & $a$ \\
\hline \multicolumn{4}{|l|}{ School visit costs } \\
\hline Per school cost of providing an education day & $(364-925)$ & & $a, b$ \\
\hline Per school cost of a sample collection day & $(1,031-2,156)$ & & $a, b$ \\
\hline Per student tested costs & CF test only & TSD test only & \\
\hline Cost of collecting a blood specimen needed to perform genetic carrier assayg & $2.22(1.11-3.33)^{h}$ & $2.22(1.11-3.33)^{h}$ & $a$ \\
\hline Laboratory cost of biochemical and/or molecular assay(s) for genetic carrier status & $55.52(28-67)^{h}$ & $90.38(45-108)^{h}$ & $a$ \\
\hline Laboratory cost of assay for CF carrier status for those of Ashkenazi Jewish ancestry & $111.13(56-133)^{h}$ & $\ldots$ & \\
\hline Cost of notifying a positive result & $10.19(5-15)^{h}$ & & $c, d$ \\
\hline Cost of notifying a negative result & $1.51(1-3)$ & & $d$ \\
\hline Cost of any additional counseling following a positive test result (on one or more tests) & $13.02(6.51-26.04)$ & & $c$ \\
\hline Cost of any additional counseling following a negative test result (on all tests) & \multirow[t]{2}{*}{$13.02(6.51-26.04)$} & & $c$ \\
\hline Costs in the "no program" submodel: & & & \\
\hline Cost of accessing screening (one standard family physician visit) & $21.29(21.29-37.57)$ & & $e$ \\
\hline Cost of obtaining specimen (with test organized via a family physician) & $17.40(10.30-26.10)$ & & $f$ \\
\hline Cost of laboratory assays assumed to be the same within and outside the program & See above & $\ldots$ & \\
\hline
\end{tabular}

${ }^{a}$ These parameter estimates are based on the program managers' and laboratory scientists' detailed descriptions of the activities, staff, and equipment involved in establishing the program, running the program, providing education and collection days, and laboratory testing processes. Resources used for initially establishing the program mainly comprised the time of the four members of the program management committee in program planning and community/school consultation meetings (recalled by two of them: for more detail see Warren and Anderson 2004).24

${ }^{b}$ These parameter estimates are based on assuming a program which is running in 10 schools, with an average of 100 year 11 students in each school.

${ }^{c}$ Positive result notification costs include any genetic counseling provided during the notification telephone call (20 minutes), plus the cost of sending the notification letter. Cost of any further genetic counseling time after result notification is 30 minutes of genetic counsellor time.

${ }^{d}$ In the base case analysis, the cost of notifying the test results is assumed to be the same for those tested under the screening program as those tested via their family physician or in a specialist centre.

${ }^{e}$ Cost of a family physician visit assumes a "bulk-billed" short visit (i.e. family physician directly claims $85 \%$ of the MBS fee from Medicare) item code $23=25.05 \times$ $0.85=\$ 21.29$.

${ }^{f}$ Cost of obtaining a blood specimen outside the school-based screening program is taken as the MBS fee (Category 6: Pathology Services Table, item code 73907, for specimen collection at a collection centre operated by the pathology practice and collected by pathology staff)

8 If both tests are received, the cost of the blood specimen is 2.22

${ }^{h}$ Low and high values are $-50 \%$ and $+50 \%$ of base case estimate. Cost of testing for CF mutations was $\$ 55.52$ for dF508 only (in CNJ and Other), or $\$ 118.52$ if testing for 16 CFTR mutations (1717-1 G->A, G542X, W1282X, N1303K, dF508, dI507, 3849+10kb C->T, S549N, G551D, R553X, R560T, R334W, R347P, A455E, $\mathrm{R} 117 \mathrm{H}, 621+1 \mathrm{G}->\mathrm{T})$, which this program did in later years. 
Asian countries); Indian; Southern European such as Greece and Southern Italy; and Other (specify). They were also told that they could indicate more than one area. For reasons of data availability and simplicity we defined only three ethnic groups: those students who identified themselves as Jewish and of Northern European ancestry were classified as Ashkenazi Jewish. All other students with a Northern European ancestry were classified as "Caucasian non-Jewish" (CNJ). The remaining students were grouped as "Other" (i.e., Asian, African, Indian, Middle-Eastern, or Southern European, including Sephardic Jews). The group-specific parameters relating to these ethnic groups are shown in Table 1.

Questionnaire surveys of students attending the compulsory education sessions (in 2000) showed the following: in Jewish schools, approximately $97 \%$ were of Ashkenazi Jewish ancestry (Jewish), $1.5 \%$ were of Caucasian Non-Jewish (CNJ) ancestry, and approximately $1.5 \%$ were of Other ancestry; in government schools in 2000, the ethnic profile was 10\% Ashkenazi Jewish, 35\% CNJ, and 55\% Other. The estimated profile of all students in the reference program was therefore $40 \%$ Ashkenazi Jewish ancestry, 25\% CNJ, and 35\% Other. Ethnic group-specific test-accepting rates for each test (Table 1) were estimated by combining these data with the numbers of students of different declared ancestry shown on forms completed by the interviewer at the sample collection day.

TSD and CF have different genetic carrier prevalence in different ethnic groups. In the model, the carrier prevalences of TSD for Ashkenazi Jewish, CNJ, and Other used are as follows: 1 in 282,$3 ; 1$ in 280; and 1 in 280, respectively. The genetic carrier prevalence of CF for Ashkenazi Jewish, CNJ, and Other are as follows: 1 in 30; 1 in 26, 28 ; and 1 in 150, ${ }^{29}$ respectively.

The sensitivity and specificity of the tests also vary with different ethnic groups. This is partly because the genetic mutations tested for will have different prevalences in different ethnic groups. In some cases, it is also because different genetic mutations are tested for in the panel of testing "kits" used by the laboratory, depending on the declared ancestry of the student. When testing for CF in individuals of Jewish ancestry, the laboratory assay tested for 6 mutations (1717-1 G->A, G542X, W1282X, N1303K, dF508, and 3849+10kbC- $>$ T), whereas in individuals of non-Jewish ancestry, the assay tested only for the dF508 mutation.

\section{Estimating effectiveness}

The measure of effectiveness used is the number of genetic carriers detected. The model estimates the number of carriers detected in the program submodel and the number of carriers detected in the absence of the program (i.e., through accessing a test via a family physician). The base case analysis (i.e., using "best" initial evidence and assumptions) gives equal value to detecting a carrier of either of the genetic conditions being tested.

The effectiveness of the screening program is estimated by the model on the basis of the following parameters: the proportion of students of different ancestry at participating schools; the genetic carrier prevalence for each disorder in each of these groups; the proportion of students who are present at the specimen collection day; the proportion of students of different ancestry who choose to be tested (for either or both disorders); test accuracy according to ancestry (sensitivity and specificity); and the proportion choosing different result notification schemes (including the estimated proportion who choose delayed notification but then will forget to obtain their result). The value and source of these parameters is shown in Table 1. The probabilities that determine the effectiveness of the hypothesized "no program" submodel were primarily developed from discussions with the program managers and were varied extensively in the sensitivity analysis.

The screening program submodel assumes that all students who are at school on the collection day are offered testing, but that a small proportion of students might be absent ( $9 \%$ in the base case). Based on data from the Sydney school screening program, the model determines whether a student of particular ancestry chooses to have genetic carrier testing for TSD, CF, both disorders, or neither. If a student chooses to be tested for carrier status of either disorder, the model also allows one of three result notification schemes to be followed. It is assumed that students who choose to retrieve their test result in the future, do so after 10 years (varied between 5 and 18 years in the univariate sensitivity analysis). Students who are not offered testing (due to absence) or those who chose not to be tested for genetic carrier status via the screening program, may still access genetic carrier testing at a later date (e.g., via a family physician; in the base case, 10 years later).

In the Sydney school screening program, of those students who received testing, the majority of students elected to receive their results immediately (Table 1). It is likely that some of the students who elected to receive their result at a later date will, for various reasons, not access their test result (we assumed $40 \%$ in the base case). Of students who chose a delayed result, $20 \%$ chose to be in the "anonymous couple" notification scheme, and $80 \%$ deferred their decision regarding their notification options. The model also assumes that all students who defer this decision ultimately choose to receive an individual result.

In the no program submodel, in the absence of evidence from other potential sources, we have made the following simplifying assumptions relating to test-accessing behavior. If an individual accesses testing, they start by accessing testing for either TSD or CF (although, having sought a TSD carrier test, someone of Jewish ancestry might also be offered the CF test). The base case assumes that $5 \%$ of individuals of Ashkenazi Jewish ancestry would, of their own accord, access genetic testing for TSD before starting a family. Of these, it assumes that $80 \%$ would be offered and also choose to be tested for CF (in the Sydney school screening program this is the proportion of Jewish students who choose testing for both TSD and CF carrier status). However, it is assumed that if testing for TSD is not accessed, neither is testing for CF (i.e., no Ashkenazi Jewish choose to have $\mathrm{CF}$ carrier testing only). It was assumed that no individuals of $\mathrm{CNJ}$ or Other ancestry would access genetic testing for TSD, but $1 \%$ would access genetic testing for CF (Table 
1). Testing is assumed to occur 10 years in the future (varied between 5 and 18 years in the sensitivity analysis).

\section{Estimating and valuing resource use}

The cost of providing the screening program has been estimated using a "micro-costing" approach. ${ }^{30}$ This involves building up a detailed listing of the types of resource that are used in providing the program, measuring or estimating the amount of each resource used, and then valuing those resource units appropriately.

Costs in the model include the following (Table 2): a share of those incurred in establishing the program (one-off costs incurred in the months and years before the program being launched); annual overhead costs of program management (i.e., those incurred irrespective of the number of participating schools or students); arrangement, updating, and provision of education sessions and specimen collection; genetic testing (clerical processing of forms, laboratory processing of blood samples); checking and notification of test results (including genetic counselor telephone time for positive results); and other flow-on costs following testing (e.g., further genetic counseling, and the storage of test results and genetic material). These costs were sourced from the administrative records and management team of the program, unless otherwise indicated in the table footnotes, and are in 2003 Australian dollars.

In the "no program" submodel, the cost of testing for TSD or CF includes one standard family physician consultation. It is assumed that the cost of performing a genetic carrier test for TSD or CF is the same irrespective of whether the test is taken as part of a screening program or not. In the "no program" submodel, we assume that the sample taking and test is performed by a private pathology company. Sample taking is costed using the Australian Government's cost rebate system (Medicare) for pathology services. The model assumes that the cost of result notification or any additional counseling is the same as in the program submodel (i.e., positive results are no- tified by a phone call from a genetic counselor, whereas negative results are notified by a letter).

\section{Data analysis and sensitivity analysis}

Future costs were discounted at a rate of $5 \%$, the conventional rate in Australia for the economic appraisal of health technologies. ${ }^{31}$ Health sector cost savings, due to affected births avoided, were not included in this analysis because the time horizon of this study is from the present up to the point when people are assumed to start families (i.e., knowledge of genetic carrier status is the outcome of interest at this stage). Future benefits, in terms of genetic carriers detected were not discounted because the timing of the potential use of the information (i.e., before marriage or before starting a family) should be approximately the same regardless of when the knowledge about carrier status was acquired.

We used sensitivity analysis to assess the impact on the main cost-effectiveness estimate of changing variable values that are known to be uncertain. We also conducted a second set of policy scenario analyses comparing the base case current screening program with various alternative specifications of the "no program" alternative.

\section{RESULTS}

The base case cost-effectiveness results are shown in Table 3. The model estimates that, for a "mixed" schools program of 10 schools (4 Jewish, 6 government; each with an average of 100 students in year 11), the screening program will detect an estimated 10.2 TSD carriers and 14 CF carriers per year (24.2 genetic carriers of either disorder). For the same hypothetical cohort of 1,000 students, only 1.3 genetic carriers would be detected without the program (largely because so few are assumed to access testing). Thus, the school screening program detects 23 additional genetic carriers (Table 3 ). The annual total cost of the screening pro-

Table 3

Base case incremental cost-effectiveness results

\begin{tabular}{|c|c|c|c|c|c|}
\hline Policy & $\begin{array}{l}\text { Total cost } \\
\text { (per } 1000 \\
\text { students) }\end{array}$ & $\begin{array}{c}\text { Total carriers } \\
\text { detected } \\
(\text { per } 1000)^{a}\end{array}$ & $\begin{array}{c}\text { Incremental } \\
\text { cost }(A \$)\end{array}$ & $\begin{array}{l}\text { Incremental } \\
\text { effectiveness }\end{array}$ & $\begin{array}{l}\text { Incremental } \\
\text { CE ratio }\end{array}$ \\
\hline \multicolumn{6}{|c|}{ With costs and benefits discounted (5\%) } \\
\hline No screening program & $\$ 3,100$ & 0.8 & & & \\
\hline Reference program & $\$ 137,000$ & 23.9 & $\$ 133,900$ & 23.1 & $\$ 5,801$ \\
\hline \multicolumn{6}{|c|}{ With only costs discounted (5\%) } \\
\hline No screening program & $\$ 3,100$ & 1.3 & & & \\
\hline Reference program & $\$ 137,000$ & 24.2 & $\$ 133,900$ & 23.0 & $\$ 5,834$ \\
\hline \multicolumn{6}{|l|}{ Undiscounted results } \\
\hline No screening program & $\$ 5,000$ & 1.3 & & & \\
\hline Reference program & $\$ 137,300$ & 24.2 & $\$ 132,200$ & 23.0 & $\$ 5,759$ \\
\hline
\end{tabular}

${ }^{a}$ There were assumed to be approximately 1000 students in the current "mixed"--Jewish and Government--schools program. 
gram estimated by the model is $\$ 137,000$, compared with a cost of $\$ 3,100$ for the alternative, "no screening program" (incremental cost: $\$ 133,900)$. Therefore, compared to the no-screening program, the incremental cost per additional carrier detected by the screening program is therefore $\$ 5,834(\approx 133,900 / 23$ ) with costs discounted at $5 \%$ per year, $\$ 5,759$ with no discounting, and $\$ 5,801$ with both future costs and effectiveness discounted at $5 \%$ per year.

\section{Sensitivity analysis}

The one-way sensitivity analysis showed that many of the variables had little impact on the cost-effectiveness ratio. Of the parameters varied, nine altered the base case incremental cost-effectiveness ratio by more than $5 \%$. If each CF genetic carrier detected was valued at half the value of a TSD genetic carrier, the incremental CE ratio increases over $40 \%$ (to $\$ 8250$ per weighted-carrier detected). If the per-sample cost of all laboratory assays were half current estimates (i.e., TSD $\$ 45$ and CF $\$ 27$, or $\$ 55$ for the 16-mutation CFTR assay) the incremental cost-effectiveness would reduce to $\$ 3958$ per carrier detected (a $32 \%$ reduction). Other parameters with significant impact on the incremental cost-effectiveness ratio were as follows: the proportion of Jewish individuals who have testing for TSD (in both the screening program and comparator submodels), the annual running costs of the program, and the cost of sample collection days--these all altered the base-case costeffectiveness ratio by around 5\%. For example if only $60 \%$ (instead of $80 \%$ ) of Jewish students choose to be tested for TSD, then the incremental cost-effectiveness increases by $6 \%$ to $\$ 6182$ per carrier detected.

The sensitivity and specificity of the genetic tests also had a significant impact on the incremental cost-effectiveness ratio. If the accuracy of both the TSD and CF genetic tests were less than our base-case parameters, the cost per additional carrier detected increased to $\$ 9369$. [This estimate is based on the following: sensitivity of the test for TSD reducing to 0.75 (Jew- ish), 0.30 (CNJ), and 0.05 (NC); specificity of TSD test increasing to 0.999 for all three groups; and sensitivity of the test for $\mathrm{CF}$ reducing to 0.28 for Jewish and to 0.70 (from 0.75) for CNJ.]

\section{Exploring alternative assumptions about the "no screening program" scenario}

Table 4 shows the impact on the cost-effectiveness ratio of alternative assumptions relating to the no screening program scenario. The most uncertain assumptions about how genetic carrier testing would occur in the absence of the school-based program relate to the proportion of people who would access testing of their own accord, and the extent to which testing people on the basis of individual requests is more costly (per person tested) than testing within a systematic program (i.e., where screening involves the large-scale collection and testing of samples). With the scenarios selected, the incremental costeffectiveness ratio of moving from no screening program to school-based screening varies by only $12 \%$ from the base case estimate (up to $\$ 6534$ per carrier detected). However, these analyses do not include any cost for the activities required to achieve these highly optimistic "background" levels of genetic carrier testing without the screening program.

\section{DISCUSSION}

This study is the first economic evaluation of preconceptional genetic carrier screening to evaluate a combined program that offers education and school-based carrier testing for several genetic disorders, and which allows the ethnic profile of the target population to be systematically varied. It is also, to our knowledge, the first economic evaluation of any genetic carrier testing program in an Australian community. The organized screening program is expected to increase the number of carriers detected from around 1 per 1000 (with no program) to 24 per 1000 students. The incremental cost-effectiveness of

Table 4

Scenario analysis results: Alternative no screening program scenarios compared with reference screening program

\begin{tabular}{|c|c|c|c|c|c|}
\hline Base case analysis & $\begin{array}{l}\text { Total cost } \\
(\text { per } 1000 \\
\text { students })^{a}\end{array}$ & $\begin{array}{c}\text { Total carriers } \\
\text { detected (per } \\
1000 \text { students) }{ }^{a}\end{array}$ & $\begin{array}{l}\text { Incremental } \\
\operatorname{cost}(\mathrm{A} \$)^{b}\end{array}$ & $\begin{array}{l}\text { Incremental } \\
\text { effectiveness }\end{array}$ & $\begin{array}{c}\text { Incremental } \\
\text { CE ratio }{ }^{b}\end{array}$ \\
\hline $\begin{array}{l}\text { No screening program as specified in base case ( } 5 \% \text { Ashkenazi } \\
\text { Jewish access TSD test; } 1 \% \text { CNJ and Other access CF test) }\end{array}$ & $\$ \quad 3,100$ & 1.3 & & & \\
\hline Reference screening program & $\$ 137,000$ & 24.2 & $\$ 133,900$ & 23.0 & $\$ 5,834$ \\
\hline $\begin{array}{l}\text { No screening program ( } 10 \% \text { of Ashkenazi Jewish accessing } \\
\text { TSD testing, and } 5 \% \text { of CNJ accessing CF testing) }\end{array}$ & $\$ \quad 6,400$ & 2.8 & & & \\
\hline Reference screening program & $\$ 137,600^{c}$ & 24.4 & $\$ 131,200$ & 21.6 & $\$ 6,051$ \\
\hline $\begin{array}{l}\text { No screening program ( } 20 \% \text { of Ashkenazi Jewish accessing } \\
\text { TSD testing, and } 10 \% \text { of CNJ accessing CF testing) }\end{array}$ & $\$ 12,600$ & 5.5 & & & \\
\hline Reference screening program & $\$ 138,600^{c}$ & 24.8 & $\$ 126,000$ & 19.3 & $\$ 6,534$ \\
\hline
\end{tabular}

${ }^{a}$ Based on the 1000 students in the current "mixed" school screening program. Future costs discounted at 5\% per year (e.g., costs of testing under the no screening program strategies).

${ }^{b}$ The incremental cost-effectiveness of the current "mixed" school screening program relative to the no school-based screening program strategies shown.

${ }^{c}$ The cost and effectiveness of the reference screening program submodel changes from scenario to scenario since this sub-model includes some pathways, for instance, students absent from school on the screening day, that lead to the no screening submodel (see Fig. 1). 
the program, relative to no school-based program, is approximately $\mathrm{A} \$ 6000$ per genetic carrier detected, and this implies a cost per affected birth avoided of approximately half a million Australian dollars. The analysis also provides an estimate of the total cost of introducing and running such a school-based program.

Do these program outcomes justify their cost? The conventional outcomes used in health economic evaluations-lifeyears gained, or quality-adjusted life-years (QALYs) —are rarely used for evaluating the prevention of genetic disorders where the primary outcome of screening is information (although, see Rowley et al. ${ }^{10}$ for an exception). Genetic carrier screening conducted preconceptionally produces information that may be used to influence reproductive behavior; at-risk couples can avoid having affected children by not having children, by using assisted reproduction techniques, or by terminating affected pregnancies. ${ }^{32}$ Measuring or estimating the number of genetic carriers detected preconceptionally is thus an intermediate measure of potential health benefits. Nor does it capture or value the benefits of avoiding affected births, the value of making more informed reproductive choices, or any "reassurance value" for people knowing they are not a carrier. ${ }^{33}$ Nevertheless, given the current paucity of reliable data on whether and how knowledge of carrier status will be used to influence reproductive behavior (e.g., rates of recall of information, effects on choice of partner, effects on family size, level of use of reproductive assistance allowing unaffected embryo selection etc.), we have deliberately limited our main analysis to estimating the cost per carrier detected.

Knowledge about genetic carrier status through genetic testing is not a universally accepted policy goal. However, the main goal of preconceptional carrier genetic testing is to avoid the birth of affected children with serious genetic condition(s). We therefore provide a brief illustration of how the cost per carrier detected results could be extended, and this allows a preliminary comparison with studies that have assessed the cost-effectiveness of prenatal screening.

To estimate the cost per affected child avoided, we first assumed that three-quarters of students who are found by the program to be genetic carriers would go on to have families, and that their partner has a 1 in 30 chance of also being a carrier for the same disorder (i.e., assuming a relatively high, but not $100 \%$, likelihood of students choosing a partner from the same ethnic group). Further, we assumed that each at-risk couple would, on average, have two children (each with a 1 in 4 chance of having the genetic disorder). Their probability of having an affected first child would be $3 / 4 \times 1 / 30 \times 1 / 4=1$ in 160 ; the probability of the second child being affected would be $3 / 4 \times$ $1 / 30 \times 3 / 4 \times 1 / 4=9$ in 1920 . Therefore, the probability of having an affected child in either of the two pregnancies would be $12 / 1920+9 / 1920 \approx 1$ in 91 .

Thus, if knowledge of carrier status influenced reproductive behavior in all such couples, so that an affected child was not born, our base case estimate of $\$ 5,834$ per additional carrier detected by the program would imply a cost per TSD or CF birth avoided of about $\$ 530,000(\approx$ US $\$ 371,000$ with an exchange rate of 0.7$)$. This is broadly similar to the estimated discounted lifetime medical care costs of people living with CF (US $\$ 300,000$ to US $\$ 500,000)$. $^{7,10,12,34}$ It also compares favorably with the cost per CF case detected via prenatal screening in the US (US\$400,000-\$500,000 for non-Hispanic Caucasians and Ashkenazi Jewish), ${ }^{34}$ and Denmark..$^{35}$

However, making similar cost comparisons for lives with TSD avoided would be more contentious than it is for CF; being untreatable and so rapidly fatal, lives with TSD may be relatively much less medically costly than lives with $\mathrm{CF}$, but the severity of mental and physical effects (in the child affected and their parents) should, arguably, make the value of preventing TSD births much higher. This highlights the major problem, facing all evaluations of programs that have multiple objectives, of how to relatively "weight" the value of knowing genetic carrier status for different disorders. One approach might be to first value the benefits to couples of avoiding the births of children with different disorders, and derive from this the average value of genetic carrier status knowledge.

School-based screening programs may be very effective in terms of achieving the outcomes of offering access to genetic testing, resulting in high uptake and detection rates of genetic carrier status in schools that attract a large proportion of students from particular ethnic communities. However, they may not be the most cost-effective method for discovering genetic carrier status in the wider, more ethnically mixed population. Some studies suggest that preconceptional carrier screening offered via a primary care setting is more efficient. ${ }^{12}$ One possible scenario would be the emergence of a public education program in which awareness of these disorders and tests are promoted to the general population, for example by family physicians/medical practitioners, or other primary care practitioners. Whether adequate uptake rates are achievable, and at similar or lower cost, can only be conclusively established by a well-evaluated family physician-based public educational program to promote genetic carrier screening. A previous Australian study using a family physician-based screening strategy supplemented by a public educational program to promote genetic carrier screening ${ }^{36}$ did not achieve sufficient uptake rates to justify its continuation; indeed, that program's results were the stimulus for developing the schools-based screening program described in this article.

\section{Study limitations}

The main limitation of this model is the lack of reliable data relating to some parameter estimates. Evidence about what genetic testing would take place in the absence of the schoolbased screening program is particularly lacking: we have therefore varied these assumptions widely in the sensitivity and scenario analysis. Sometimes sensitivity analysis is used to explore the circumstances under which the policy decision would alter, for example, to identify the assumptions under which a particular strategy becomes both more costly and less effective than an alternative. However, because school-based genetic screening is both so much more effective and so much more costly than the no screening program, sensitivity analysis in this context can only identify which variables have the greatest impact 
on the incremental cost-effectiveness ratio. Due to the lack of individual-level data on costs and effectiveness under the alternative strategies, only simple one-way and two-way sensitivity analyses were possible; future modeling of these policy choices should endeavor to obtain data that would allow the conduct of probabilistic sensitivity analysis. ${ }^{37}$

Crucial to the modeled effectiveness of a school-based screening program is the assumption that those tested at school will recall or, if they have delayed result notification, access, their test results later in life. Few studies have assessed this, but one Australian study ${ }^{13}$ has shown that education and testing at school does result in higher retained (after 3-6 years) knowledge of the conditions screened for in the programs; whereas in a Canadian study in Montreal, ${ }^{3}$ genetic counseling was used many years later in pregnancy by those who were found to be genetic carriers through school testing. However, other research into the long-term (after 3 years) recall and meaning of genetic carrier test results for CF has shown poor accuracy of recall and no effect on reproductive intentions or behavior. ${ }^{38}$

This analysis has focused only on costs up to the point of genetic carrier detection. In studies of prenatal CF carrier screening, the treatment costs of affected children avoided have typically been deducted as savings made by the program. ${ }^{7,10,12}$ Such estimates are invariably crude and also give no value to lives lived with CF. Further, applying a similar approach to TSD might-in a cost-effectiveness analytical framework that compares programs aimed at different genetic disorders — effectively value CF births avoided more highly than TSD births avoided (solely because of the greater health sector savings that they generate). Counting such savings without also including in the analysis the difference in quality-adjusted life-years between lives lived with and without each disorder would, we believe, not provide a fair comparison of the screening policies.

For similar reasons, we have only discounted carriers detected in the future in the base case analysis. Whether to discount future health effects is a contentious methodological issue in cost-effectiveness analysis..$^{39,40}$ Because knowledge of carrier status is an inherently intermediate outcome measure (and can not, yet, be regarded as a health effect), and because we do not want arbitrarily to give greater value to carriers detected earlier rather than later in life, we have decided not to discount them in most of our analyses. If, in the future, this analysis is extended to incorporate quality- and length-of-life estimates of affected births avoided then the decision about whether to discount these future benefits should be reconsidered.

Other limitations of this study are the following: the exclusion of cascade screening (where other family members access carrier screening due to an increased knowledge of the disorders, or a positive result); the lack of comparisons between preconceptional and prenatal screening policies (often viewed as the two key policy alternatives); the assumption that Jewish students in the no program submodel would not access genetic carrier testing for CF unless they were accessing TSD testing; the omission of estimated savings due to prenatal testing avoided (which, for various physiological reasons, is much more expensive than preconceptional genetic carrier testing); and also the lack of value given to the educational component of the program (i.e., in addition to their effect on test take-up rates). Cascade screening of family members would certainly increase the estimated effectiveness of the school-based program (i.e., more carriers would be detected), but the impact on cost-effectiveness would critically depend on how much more expensive it is to have the genetic test outside the program. The cost-effectiveness from a health system perspective would further depend on whether the cost of the test was borne by the family members. With better data from more than one existing program, we could have made less simplistic assumptions about these issues, and the likely costs and effects of scaling up the program to cover more schools. Our companion Research Report makes some preliminary estimates of how simultaneous changes in the scale of the program (i.e., number of schools) and the ethnic mix of participating students affects the incremental cost-effectiveness of school-based screening. ${ }^{41}$

Our study has demonstrated the general value of decisionmodeling for the quantitative exploration of the benefits and costs of specific program changes. The same model could explore the impact on costs and effectiveness of more specific changes within the program: such as switching from a blood sample for TSD testing to a mouthwash sample (i.e., higher test take-up rate due to "no needles") or of offering testing for another disorder (e.g., thalassemia as well as TSD and CF).

Finally, we note that genetic carrier screening in senior High Schools has been adopted to varying degrees in different countries. While common in parts of Canada, and now also in Australia, it is yet to be widely adopted in other parts of the world-in some part due to different health care systems and policies regarding age of consent for testing..$^{14,42}$ Our data may be useful in informing health policy planners of the potential benefits and cost effectiveness of this mode of delivering genetic information to those in the population who are most likely to use it.

\section{ACKNOWLEDGMENTS}

The research reported in this paper was funded by an NHMRC Project Grant 9937376. Also, the generous financial support of the Wolper Jewish Hospital is acknowledged for the reference program. The authors would like to acknowledge contributions from Dr. Philippe Beutels (for helpful comments on an earlier draft), Dr. Lisa Koe (Pathologist, PaLMS), and others who supplied cost or other data. The four directors of the screening program are the authors L.B., A.P., K.B.-S., and Harry Aizenberg of the Wolper Jewish Hospital, Woollahra, Sydney.

Potential competing interests: Three of the authors (LB, AP and KB-S) have continuing honorary involvement (i.e., nonrecompensed) in the operation and management of the screening program which is the basis of the reference screening program evaluated in this paper. There are no other competing interests. 


\section{Appendix}

\section{Box 1. Main features of the reference genetic carrier screening} program

- Screening program offers tests to detect genetic carrier status for TSD and/or CF.

- Screening is offered to 16- and 17-year-old students in their penultimate year of high school.

- An education session about the disorders, their prevalence, the nature of genetic tests, and information on how to access testing is provided prior to the testing by a genetic counselor or genetics educator. Attendance at the education session is compulsory for all students in the year.

- Two to ten days later, at a specimen collection day, students may accept screening for none, one or both of the tests offered. Participation in screening is voluntary and students provide signed consent. Parental consent is only required for the few students yet to reach 16 years.

- Students can choose to have their test results notified immediately (when the laboratory has completed analysis), delay the timing of notification (indefinitely, until an unspecified future data selected by the student), or enter an "anonymous couple scheme" (where the couple is informed only if they are at risk of having an affected child i.e., if they are both genetic carriers for the same genetic disorder).

- Individuals, with the exception of those in the "anonymous couple scheme," are notified (immediately or later) of their test result irrespective of whether the result is positive (by a phone call from a genetic counselor followed by a letter confirming their result status) or negative (by letter).

- If students have testing for both disorders, the notification of both results will occur simultaneously.

- Students are offered additional genetic counseling at a later date irrespective of whether the result is positive or negative. Cascade testing of other family members is offered to those with a positive genetic carrier test result.
Box 2. Main features of the hypothetical no screening program scenario

- In the absence of the school-based screening program, the following is assumed:

- Accessing testing depends on it being offered by a general medical practitioner/family physician as part of usual medical care or where it is requested by the patient of their own accord, and being accepted.

- Individuals would access genetic carrier testing in much smaller numbers, and later in life (on average, we assume, 10 years later, when they are 26 or 27 years old). They would also be more likely to initially access testing for the single genetic disorder most relevant to their ethnicity.

- Specimen collection takes place in the community (e.g., at a pathology practice) but laboratory assays will all take place at the specialist center.

- Individuals are notified of their test result(s) irrespective of whether the result is positive or negative.

- Individuals can receive additional counseling at a later date irrespective of whether the result is positive or negative. 


\section{References}

1. Kaback M, Lim-Steele J, Dabholkar D, Brown D, Levy N, Zeiger K. Tay-Sachs disease - carrier screening, prenatal diagnosis, and the molecular era. An international perspective, 1970 to 1993. The International TSD Data Collection Network. J Am Med Assoc 1993;270:2307-2315.

2. Gason A, Sheffield E, Bankier A, Aitken M, Metcalfe S, Barlow-Stewart K, et al. Evaluation of a Tay-Sachs Disease screening programme. Clin Gen 2003;63:386392.

3. Mitchell JJ, Capua A, Clow C, Scriver CR. Twenty-year outcome analysis of genetic screening programs for Tay-Sachs and beta-thalassemia disease carriers in high schools. Am J Hum Gen 1996;59:793-798.

4. Wake SA, Rogers CJ, Colley PW, Hieatt EA, Jenner CF, Turner GM. et al. Cystic fibrosis carrier screening in two New South Wales country towns. Med J Australia 1996;164:471-474.

5. Welsh M, Ramsey B, Accurso F, Cutting G. Cystic Fibrosis (Ch. 201). In: Scriver C Beaudet AL, Sly WS, Valle D, editors. The metabolic and molecular bases of inherited disease. New York: McGraw-Hill, 2001: 5121-5188.

6. Merz B. Matchmaking scheme solves Tay-Sachs problem. J Am Med Assoc 1987;258: 2636-2639.

7. Asch DA, Hershey JC, Dekay ML, Pauly MV, Patton JP, Jedrziewski MK, et al. Carrier screening for cystic fibrosis: costs and clinical outcomes. Med Decis Making 1998;18:202-212.

8. Lieu TA, Watson SE, Washington AE. The cost-effectiveness of prenatal carrier screening for cystic fibrosis. Obstet Gynecol 1994;84:903-912.

9. Vintzileos AM, Ananth CV, Smulian JC, Fisher AJ, Day-Salvatore D, Beazoglou T. A cost-effectiveness analysis of prenatal carrier screening for cystic fibrosis. Obstet Gynecol 1998;91:529-34.

10. Rowley PT, Loader SS, Kaplan RM. Prenatal screening for cystic fibrosis carriers: an economic evaluation. Am J Hum Gen 1998;63:1160-1174.

11. Nelson WB, Swint JM, Caskey CT. An economic evaluation of a genetic screening program for Tay-Sachs disease. Am J Hum Gen 1978;30:160-6.

12. Wildhagen MF, Hilderink HB, Verzijl JG, Verheij JB, Kooij L, Tijmstra T, et al Costs, effects, and savings of screening for cystic fibrosis gene carriers. J Epidemiol Community Health 1998;52:459-67.

13. Barlow-Stewart K, Burnett L, Proos A, Howell V, Huq F, Lazarus R, et al. A genetic screening programme for Tay-Sachs disease and cystic fibrosis for Australian Jewish high school students. J Med Genet 2003;40:e45.-

14. McCabe L. Efficacy of a targeted genetic screening program for adolescents [editorial; comment]. Am J Hum Gen 1996;59:762-763.

15. Motulsky AG. Screening for genetic diseases. N Engl J Med 1997;336:1314-1316.

16. Australian Bureau of Statistics. 2001 Census Basic Community Profile and Snapshot: Snapshot of Sydney. 2002, Australian Bureau of Statistics: Canberra. Available at: http:// www.abs.gov.au/Ausstats/abs@census.nsf/Census_BCP_Free_ASGC_ViewTemplate! ReadForm\&Start $=1 \&$ Count $=1000 \&$ Expand $=1.1$ Accessed May 19, 2005.

17. Buxton M, Drummond M, van Hout B, Prince R, Sheldon T, Szucs T, et al. Modelling in economic evaluation: an unavoidable fact of life. Health Econ 1997;6:217227

18. Keeler E. Decision trees and Markov models in cost-effectiveness research. In: F. Sloan, Editor. Valuing health care: costs, benefits and effectiveness of pharmaceuticals. Cambridge: Cambridge University Press, 1995: 185-205.

19. Cooper J, Franks A. Screening for cystic fibrosis. Screening before pregnancy is preferred. BMJ 1994;309:339-340.

20. American College of Obstetrics and Gynecology. Ob-Gyns offering large-scale cystic fibrosis screening (ACOG News Release: 12 December 2001). 2001. Available at: http://www.acog.org/from_home/publications/press_releases/nr12-12-01-2.cfm Accessed May 19, 2005

21. NIH Consensus Development Panel on Genetic Testing for Cystic Fibrosis. Genetic Testing for Cystic Fibrosis [National Institutes of Health Consensus Development Conference on Genetic Testing for Cystic Fibrosis]. Arch Intern Med, 1999;159: 1529-1539.

22. Eng CM, Schechter C, Robinowitz J, Fulop G, Burgert T, Levy B, et al .Prenatal genetic carrier testing using triple disease screening. J Am Med Assoc 1997;278:12681272.
23. Kuntz K, Weinstein MC. Modelling in economic evaluation. In: Drummond M, McGuire A, editors. Economic Evaluation in Health Care: Merging theory with practice. Oxford: Oxford University Press, 2001: 141-171.

24. Warren E, Anderson R. Description of a model for investigating the cost-effectiveness of a school-based genetic carrier screening program [CHERE Research Report series, No. 23]. 2005, Centre for Health Economics Research and Evaluation, University of Technology, Sydney: Sydney. (downloadable from: http://datasearch. uts.edu.au/chere/research/research_reports.cfm)

25. Bekker H, Modell M, Denniss G, Silver A, Mathew C, Bobrow M, et al. Uptake of cystic fibrosis testing in primary care: supply push or demand pull? [see comment]. BMJ 1993;306:1584-1586.

26. Watson EK, Mayall E, Chapple J, Dalziel M, Harrington K, Williams C, et al. Screening for carriers of cystic fibrosis through primary health care services. BMJ 1991;303: 504-507.

27. Payne Y, Williams M, Cheadle J, Stott NC, Rowlands M, Shickle D, et al. Carrie screening for cystic fibrosis in primary care: evaluation of a project in South Wales. The South Wales Cystic Fibrosis Carrier Screening Research Team. Clin Gen 1997; 51:153-163.

28. Bobadilla JL, Macek Jr. M, Fine JP, Farrell PM. Cystic fibrosis: a worldwide analysis of CFTR mutations-correlation with incidence data and application to screening. Hum Mutation 2002;19:575-606.

29. Wong L-J, Wang B-T, Lee M-H, Lo S-Y. Two novel null mutations in a Taiwanese cystic fibrosis patient and a survey of East Asian CFTR mutations. Am J Med Genet 2003;120A:296-298.

30. Drummond MF, O'Brien B, Stoddart GL, Torrance GW. Methods for the Economic Evaluation of Health Care Programmes, 2nd ed. New York: Oxford University Press, 1997.

31. Commonwealth Department of Health and Ageing. Draft second revision of the manual of resource items and their associated costs (for use in major submissions to the Pharmaceutical Benefits Advisory Committee involving economic analyses). 2002, Commonwealth Department of Health and Ageing: Canberra. Available at: http://www.health.gov.au/internet/wcms/publishing.nsf/Content/health-pbs-general-pubs-manual-content.htm Accessed May 19, 2005.

32. Asch DA, Hershey JC, Pauly MV, Patton JP, Jedrziewski MK, Mennuti MT. Genetic screening for reproductive planning: methodological and conceptual issues in policy analysis. Am J Pub Health 1996;86:684-690.

33. Hall J, Viney R, Haas M. Taking a count: the evaluation of genetic testing. Aust NZ J Pub Health 1998;22:754-758.

34. Haddow J, Palomaki G. Population-Based Prenatal Screening for Cystic Fibrosis via Carrier Testing: ACCE Reciew (Draft: Version 2002.6). 2002, Centers for Disease Control and Prevention: Atlanta. Available at: http://www.cdc.gov/genomics/gtesting/ACCE/fbr.htm Accessed May 19, 2005.

35. Nielsen R, Gyrd-Hansen D. Prenatal screening for cystic fibrosis: an economic analysis. Health Econ 2002;11:285-299.

36. Burnett L, Proos AL, Chesher D, Howell VM, Longo L, Tedeschi V, et al. The Tay-Sachs disease prevention program in Australia: Sydney pilot study. Med J Australia 1995;163:298-300.

37. Briggs A. Handling uncertainty in economic evaluation and presenting the results. In: Drummond M, McGuire A, editors. Economic evaluation in health care: merging theory with practice. Oxford: Oxford University Press, 2001: 172-214.

38. Axworthy D, Brock DJ, Bobrow M, Marteau TM. Psychological impact of population-based carrier testing for cystic fibrosis: 3-year follow-up. UK Cystic Fibrosis Follow-Up Study Group. Lancet 1996;347:1443-1446.

39. Lipscomb J, Weinstein M, Torrance G. Time preference. In: Gold M, Siegel JE, Russell LB, Weinstein MC, editors. Cost-effectiveness in health and medicine. New York: Oxford University Press, 1996: 214-246.

40. Gravelle H, Smith D. Discounting for health effects in cost-benefit and cost-effectiveness analysis. Health Econ 2001;10:587-599.

41. Warren E, Anderson R, Burnett L, Proos A, Barlow-Stewart K, Hall J. The costeffectiveness of a school-based TSD and CF genetic carrier screening program in Sydney, Australia [CHERE Research Report series, No. 24]. 2005, Centre for Health Economics Research and Evaluation, University of Technology, Sydney: Sydney. (downloadable from: http://datasearch.uts.edu.au/chere/research/research_reports.cfm)

42. Khoury M, McCabe L, McCabe E. Population screening in the age of genomic medicine. N Engl J Med 2003;348:50-58. 